\title{
2 Shallowly driven fluctuations in lava lake outgassing (gas pistoning),
}

\section{Kīlauea Volcano}

4

5

6 Matthew R. Patrick ${ }^{1 *}$, Tim Orr ${ }^{1}$, A.J. Sutton ${ }^{1}$, Einat Lev $^{2}$, Wes Thelen ${ }^{1}$, David Fee $^{3}$

$9{ }^{1}$ Hawaiian Volcano Observatory-U.S. Geological Survey, PO Box 51, Hawai'i National Park,

$10 \quad$ HI, 96718

11

$12 \quad{ }^{2}$ Lamont-Doherty Earth Observatory, 61 Rte. 9w, Palisades, NY, 10964

13

$14{ }^{3}$ Wilson Infrasound Observatories, Geophysical Institute, University of Alaska Fairbanks, 903

15 Koyukuk Drive, Fairbanks, AK, 99775

16

17

18 *Corresponding author:

19

20 mpatrick@usgs.gov

21 Phone: 1-808-345-0485

22 Fax: 1-808-967-8890

23 


\section{Abstract}

27 Lava lakes provide ideal venues for directly observing and understanding the nature of

28 outgassing in basaltic magmatic systems. Kīlauea Volcano’s summit lava lake has persisted for

29 several years, during which seismic and infrasonic tremor amplitudes have exhibited episodic

30 behavior associated with a rise and fall of the lava surface ("gas pistoning"). Since 2010, the

31 outgassing regime of the lake has been tied to the presence or absence of gas pistoning. During

32 normal behavior (no gas pistoning), the lake is in a "spattering" regime, consisting of higher

33 tremor amplitudes and gas emissions. In comparison, gas piston events are associated with an

34 abrupt rise in lava level (up to $20 \mathrm{~m}$ ), during which the lake enters a "non-spattering" regime

35 with greatly decreased tremor and gas emissions. We study this episodic behavior using long-

36 term multidisciplinary monitoring of the lake, including seismicity, infrasound, gas emission and

37 geochemistry, and time-lapse camera observations. The non-spattering regime (i.e. rise phase of

38 a gas piston cycle) reflects gas bubbles accumulating near the top of the lake, perhaps as a

39 shallow foam, while spattering regimes represent more efficient decoupling of gas from the lake.

40 We speculate that the gas pistoning might be controlled by time-varying porosity and/or

41 permeability in the upper portions of the lava lake, which may modulate foam formation and

42 collapse. Competing models for gas pistoning, such as deeply sourced gas slugs, or dynamic

43 pressure balances, are not consistent with our observations. Unlike other lava lakes which have

44 cyclic behavior that is thought to be controlled by deeply sourced processes, external to the lake 45 itself, we show an example of lava lake fluctuations driven by cycles of activity at shallow depth 
46 and close to the lake's surface. These observations highlight the complex and unsteady nature of

47 outgassing from basaltic magmatic systems.

49 Keywords: lava lake, Kilauea, volcano monitoring, gas emissions

\section{1. Introduction}

53 Persistent lava lakes provide a stable window into magmatic processes such as convection and

54 outgassing dynamics. In recent years numerous studies have focused on a handful of lava lakes,

55 including Erebus (Oppenheimer et al., 2009), Erta 'Ale (Oppenheimer and Yirgu, 2002; Harris et

56 al., 2005; Spampinato et al., 2008) and Nyiragongo (Spampinato et al., 2013). With the

57 reappearance of lava lake activity in Halema'uma'u Crater, on Kīlauea Volcano, Hawai'i, over

58 the last several years (Patrick et al., 2013), there is a new opportunity to conduct

59 multidisciplinary studies on lava lake behavior. The existing robust monitoring network on

60 Kîlauea, augmented by regular visual observations of the lava lake, provides a diversity and

61 abundance of data to test models of lava lake behavior.

63 The current eruption in Halema'uma'u Crater began in March 2008 (Wilson et al., 2008; Fee et

64 al., 2010; Patrick et al., 2013), with the opening of the "Overlook" crater (Fig. 1). Ephemeral

65 lava ponds were present deep in the crater ( $200 \mathrm{~m}$ below the Overlook crater rim) during 2008

66 and 2009, with a larger, continuously active lava lake appearing in February 2010. By 2013 the

67 lake measured about $160 \times 200 \mathrm{~m}$ in size, and was normally about 30-60 m below the Overlook

68 crater rim. The lake surface consisted of large, black crustal plates separated by narrow, 
69 incandescent cracks. Lake surface migration was normally from north to south, with

70 downwelling along the southern margin and spattering commonly active at a point along that

71 edge. Rockfalls occasionally impacted the lake and triggered small explosive events (Orr et al.,

72 2013). The $\mathrm{SO}_{2}$ emission rate from the lava lake ranged between 500 and $5000 \mathrm{t} \mathrm{d}^{-1}$, with the

73 plume lofting up to a kilometer above the volcano as it was carried southwest by the prevailing

74 tradewinds (Elias and Sutton, 2012).

76 Episodic tremor was first observed in April 2008, just a month after the start of the eruption, as

77 occasional cigar-shaped tremor bursts lasting a few minutes (Patrick et al., 2008). Through 2008

78 this episodic behavior became more intense and periodic, occurring every 5-10 minutes, and was

79 associated with a rise and fall of the lava lake surface. Following the establishment of the

80 continuously active lava lake in early 2010, these joint fluctuations in tremor and lava level were

81 more sporadic (a few per day), and longer lasting (several hours each) (Patrick et al., 2010,

82 2014). We consider this behavior a type of gas pistoning, which is a cyclic rise and fall of the

83 lava surface commonly observed on Kīlauea (Swanson et al., 1979; Tilling, 1987; Orr and Rea,

84 2012). This study describes and interprets the gas pistoning between 2010 and 2015. There was

85 occasional variability in the styles of gas pistoning during this period, and we focus on the most 86 common style.

\section{2. Background}

90 We consider a gas piston event to consist of a quiescent rise of the lava surface, terminated by

91 intense spattering that accompanies an abrupt drop of the lava surface. Gas pistoning was first 
92 described in detail by Swanson et al. (1979), at Mauna Ulu, where cycles began with the

93 quiescent rise of a crusted lava surface within the conduit, taking 10-15 minutes to reach

94 maximum height (30-50 m rise). Spattering and outgassing would disrupt the surface, and the

95 lava level would rapidly drop (1-2 minutes). Swanson et al. (1979) interpreted this as gas

96 accumulating beneath an impermeable crust, building to a critical point when the crust failed and

97 gas was released, with lava draining back to fill the void.

99 Jaupart and Vergniolle (1988) and Vergniolle and Jaupart (1990) conducted analogue models to 100 suggest that gas-piston behavior was consistent with the periodic rise of large gas slugs. The rise 101 and expansion of the gas slug in the conduit would lift the lava surface and terminate with

102 bursting of the slug at the lava free surface and a rapid drop in lava level. Edmonds and Gerlach 103 (2007) analyzed gas composition during a purported gas-piston event at $\mathrm{Pu}^{`} \mathrm{u}$ ' $\mathrm{O}^{`} \overline{\mathrm{o}}$, the vent area

104 for Kîlauea's ongoing East Rift Zone eruption. The high $\mathrm{CO}_{2}$ content of the gas led them to infer 105 that the gas pistoning was driven by deeply-sourced gas slugs, supporting the Jaupart and

106 Vergniolle (1988) model and arguing against Swanson et al. (1979). Whitham et al. (2006) used

107 an analogue model to show that cyclic fluctuations in lava level might be produced by dynamic

108 pressure equilibration at the base of the conduit. Peters et al. (2014) show lava level fluctuations 109 at Erebus that may relate to this process.

111 Patrick et al. (2011a) showed that gas pistoning occurred in a perched lava channel on Kīlauea's 112 East Rift Zone in late 2007. With the perched channel removed from a deep magmatic system, 113 the shallow gas accumulation model was the only reasonable explanation for that gas-pistoning, 114 supporting Swanson et al. (1979). Patrick et al. (2010) analyzed observations of the 
115 Halema'uma'u lava lake and interpreted the behavior as due to shallow gas accumulation, which

116 was also suggested by Patrick et al. (2011b). Orr and Rea (2012) analyzed gas piston events in a

117 lava pond at $\mathrm{Pu}^{`} \mathrm{u}{ }^{`} \overline{\mathrm{O}}^{`} \mathrm{o}$ and attributed them to episodic growth and failure of a shallow foam

118 layer at the top of the lava column, irrespective of the presence of a surface crust. Chouet and

119 Dawson (2015) presented a model for Halema'uma'u gas pistoning in which foam formation

120 occurred within a narrow conduit, which is different than the lava lake scenario we describe here.

121

122 Thus, three general models have been presented to explain gas pistoning: 1) shallow gas

123 accumulation, either due to gas trapped by the surface crust (Swanson et al., 1979) or due to gas

124 trapped within a near-surface foam layer (Orr and Rea, 2012; Chouet and Dawson, 2015), 2)

125 deeply sourced gas slugs (Jaupart and Vergniolle, 1988) and 3) dynamic pressure balance

126 (Whitham et al., 2006).

\section{3. Methods}

130 We characterized the lava lake activity using five primary data sources: 1) imagery from field 131 cameras, 2) seismicity, 3) infrasound, 4) $\mathrm{SO}_{2}$ emission rates and 5) gas geochemistry.

133 We augmented direct visual observations of the lake with imagery from three cameras, two

134 visible/near-infrared and one thermal, all located on the rim of Halema'uma' $u$ Crater roughly

135 150-250 $\mathrm{m}$ from the lava lake surface. The two visible/near-infrared cameras captured images at 136 varying rates, with one having a frame rate of 1-4 frames per second (Orr et al., 2013) and the 137 other capturing an image every $10 \mathrm{~s}$ (Patrick et al. 2015a). Both operated continuously in near- 
138 infrared mode, which improves their ability to see through fume in the crater. The thermal

139 camera (HTcam) was a Mikron M7500 acquiring an image every $5 \mathrm{~s}$ with an image size of $320 \times$

140240 pixels (Patrick et al. 2014). Lava lake crust velocity was measured from the thermal images

141 using the technique of Lev et al. (2012) (Appendix). Lava level was measured using the thermal

142 images (Appendix), which provided a continuous view of the lake surface through thick fume.

143 The lava level was measured in pixels from the images manually and converted to absolute

144 height in meters (above sea level, a.s.l.) either using the camera viewing geometry and measured

145 geometry of the Overlook crater or using an empirical fit to sporadic laser rangefinder

146 measurements (Appendix).

148 Seismic data came primarily from broadband station NPT, located $\sim 700 \mathrm{~m}$ from the vent, but we 149 also used station OTL ( 2 km from vent) when NPT was not operational. Infrasound data came 150 from two sources: for the 2010 activity we used data from the University of Hawai' $i$ Infrasound 151 Laboratory infrasound array $6.8 \mathrm{~km}$ east of the vent (Fee and Garces, 2007); for activity during 1522013 and 2014 we used data from station AHUD, positioned $4.1 \mathrm{~km}$ southeast of the vent.

$154 \mathrm{SO}_{2}$ emission rates from Kîlauea caldera emission sources, principally the Overlook crater, were 155 measured by vehicle-based FLYSPEC DOAS UV spectrometer according to the method 156 described by Elias and Sutton (2012). To provide a more continuous time series reflective of $\mathrm{SO}_{2}$ 157 emission rate changes, we used data from an in-situ $\mathrm{SO}_{2}$ sensor located $200 \mathrm{~m}$ nominally

158 downwind of the vent. We monitored the chemistry of the principal gases released from the lake 159 in discrete, several-hour-long campaigns, by directing a MIDAC M4402 Open Path FTIR 160 spectrometer fitted with a Stirling-cooled InSb detector at the lake surface. The gas data time 
161 series provides a nearly continuous record of contemporaneous abundances of $\mathrm{H}_{2} \mathrm{O}, \mathrm{CO}_{2}, \mathrm{SO}_{2}$, $162 \mathrm{CO}, \mathrm{HCl}$, and $\mathrm{HF}$.

\section{4. Observations and data}

\subsection{0 activity}

168 Gas pistoning was common throughout much of 2010, and events in November-December are 169 evident as spikes in lava level superimposed on a gradually rising lava level baseline (Fig. 2a).

170 Each event was associated with tremor dropping to very low levels, a phenomenon we call

171 "tremor stagnation" that was consistently tied to gas piston events during our study period.

172 Between November 8 and December 6 there were 67 gas piston events (average of 2.4 per day), 173 ranging from 1.6 to 7.8 hours in duration (from start of rise to end of fall) with a mean of 3.4

174 hours (std. 1.1 hour). Between November 8 and 24 (after which the top of the gas piston cycles 175 went above the top of the images), gas piston events had lava level changes of 11-22 m, with a 176 mean of $15.7 \mathrm{~m}$ (std. $2.5 \mathrm{~m}$ ). Starting in mid-November, the baseline lava level began rising as

177 the summit inflated. Baseline lava level change has been tied to summit magma reservoir 178 pressure fluctuations, with the gas-driven level changes shown in this study superimposed on 179 these longer-term pressure-driven changes (Patrick et al., 2015b).

181 Figure 3 shows data from two gas piston events from November 20, 2010 (Supplementary Video 182 1), which are representative of activity from late 2010. The periods before and after the two gas 183 piston events (between 4:00 to 8:00 and 18:00 to 22:00 HST) show typical baseline behavior, 
184 with a relatively steady lava level (baseline level of $868 \mathrm{~m}$ a.s.1.) and a steady amplitude

185 envelope of moderate seismic and infrasonic tremor. The two gas piston events were associated

186 with dramatically reduced tremor amplitudes (tremor stagnation) that dropped within a minute of

187 the onset of rapid lava level rise. The rise in lava level lasted tens of minutes and slowed

188 exponentially into a lava level plateau (13-14 $\mathrm{m}$ above baseline lava level) that lasted several

189 hours. Inevitably, intense spattering would start within the lake, usually at the lake margin, and

190 corresponded with a rapid drop in lava level and a burst in seismic and infrasonic tremor. The

191 surface crust velocity showed systematic changes that correlated with lava level and tremor

192 amplitude. During steady behavior, the crust moved at a relatively constant velocity of about 0.4

$193 \mathrm{~m} \mathrm{~s}^{-1}$. For both events, the crust velocity dropped to about half of this steady velocity during the

194 rise phase, and then attained a relatively steady, yet reduced, velocity during the plateaus. Fall

195 phases were characterized by surging crust motion, with crust "plunging" towards the spattering

196 sources.

197

198 4.2. Outgassing behavior and $\mathrm{SO}_{2}$ emissions

199

200 Repeated visual observations indicate that during rise and plateau phases (i.e., tremor

201 stagnation), the outgassing plume becomes unusually thin, weak and wispy, and during the fall

202 phases (tremor burst) the plume becomes unusually thick, robust and pulsating. This difference

203 has been consistent and observed in many weather conditions, indicating the changes in plume

204 appearance are not simply driven by atmospheric conditions. In contrast, baseline lava level

205 (moderate tremor) corresponds to moderate plume vigor. Figure 4a-c shows a representative

206 example from 2013, with the same general relationship as that observed in 2010. The 
207 fluctuations in plume vigor suggest that gas emissions fluctuate concordantly with tremor. This 208 is supported by downwind $\mathrm{SO}_{2}$ concentration, used as a proxy for $\mathrm{SO}_{2}$ emission rate. Figure 5

209 shows gas piston events on November 24-27, 2010. Baseline lava level varies but is generally

210 between 870 and $875 \mathrm{~m}$ a.s.l. The baseline level is interrupted by six major gas piston events,

211 lasting between 1.9 and 4 hours, and all but one of these had lava levels that extended slightly

212 above the top of the image (equivalent to about $892 \mathrm{~m}$ a.s.l.). $\mathrm{SO}_{2}$ concentration is variable but is

213 generally between about 5 and $25 \mathrm{ppm}$ when the lava level is at its baseline level, and plummets

214 during each rise and plateau phase to undetectable levels (less than $1 \mathrm{ppm}$ ). During the fall phase

215 of the gas piston cycles the $\mathrm{SO}_{2}$ concentration briefly spikes to high levels. The relative changes

216 in $\mathrm{SO}_{2}$ emission rate implied by these $\mathrm{SO}_{2}$ concentration data are in agreement with $\mathrm{SO}_{2}$ camera

217 observations of Nadeau et al. (2014).

219 Explicit measurements of $\mathrm{SO}_{2}$ emissions from vehicle-based traverses are consistent with the in220 situ ambient $\mathrm{SO}_{2}$ concentration data and confirm that gas pistoning is associated with significant 221 changes in $\mathrm{SO}_{2}$ emission rates. Elias and Sutton (2012) showed significantly lower $\mathrm{SO}_{2}$

222 emission rates during tremor stagnation phases. We focus here on more recent data, recalibrated

223 for more accurate absolute values. Figure 4d,e shows representative emission rate changes

224 bracketing transitions between normal tremor and tremor stagnation. Tremor stagnation phases

225 in these examples have $\mathrm{SO}_{2}$ emission rates that were 23 and $38 \%$ of the values during normal

226 tremor phases, suggesting that $\mathrm{SO}_{2}$ emissions are roughly a third of that during normal tremor

227 phases. These emission rate data are again broadly consistent with the $\mathrm{SO}_{2}$ camera data of

228 Nadeau et al. (2014) and point to significantly reduced gas emissions during lava rise and plateau 229 phases of gas piston events. 


\section{4.3. Gas geochemistry}

233 FTIR data collected on January 14, 2011, captured relatively short-term, quasi-periodic gas

234 pistoning (similar to that shown in Supplementary Video 2), with 10 cycles occurring between

$235 \quad$ 10:15 and 16:15 HST (Fig. 6; Appendix). Lava level changes were 15-20 m above baseline 236 (Fig. 6a), with each cycle lasting about 30 minutes. Rise phases corresponded with a weak and

237 wispy gas plume, characterized by lower pathlength-concentrations of all gas species measured 238 by FTIR (Appendix). Fall phases were associated with a vigorous, pulsating plume and higher 239 pathlength concentrations for all species. $\mathrm{SO}_{2} / \mathrm{CO}_{2}$ drops to very low and steady values during 240 the rise phase (Fig. 6c), while during fall phases $\mathrm{SO}_{2}$ and $\mathrm{H}_{2} \mathrm{O}$ release dominates with high and 241 chaotic $\mathrm{SO}_{2} / \mathrm{CO}_{2}$ and $\mathrm{H}_{2} \mathrm{O} / \mathrm{CO}_{2}$ shown in the exsolved gases. $\mathrm{SO}_{2} / \mathrm{HCl}$ ratios spike at the onset 242 of the fall phases (Fig. 6e).

\section{$244 \quad 4.4 . \quad 2013-2015$ activity}

246 By 2013, gas piston events still consisted of long periods (hours) of tremor stagnation, but lava

247 level fluctuations were smaller in amplitude and less conspicuous. In 2013-2015, gas piston 248 events were most conspicuous by changes in tremor and spattering in the lake, and we referred to 249 lake outgassing behavior as either "spattering" (normal, moderate tremor and spattering) or 250 "non-spattering" (tremor stagnation and no spattering) phases. Non-spattering phases 251 corresponded with the rise and plateau phases of gas pistoning. Analysis of 900 non-spattering 252 phases between February 2012 and November 2013 reveals a range of durations between 4 
253 minutes and 15.8 hours, with a mean of 2.3 hours (std. 1.7 hours). During these 22 months, the

254 lava lake was in a non-spattering phase $13 \%$ of the time.

255

256 Figure 7 shows a one day period (April 5, 2014), representative of 2013-2015. The non-

257 spattering phases lasted between 1.3 and 2.6 hours, shown by mirrored reductions in seismic and

258 infrasonic tremor amplitudes. Non-spattering phases were each associated with an abrupt rise in

259 lava level by about $3 \mathrm{~m}$. The non-spattering phase that begins around 15:00 was unusual in that

260 lava level abruptly rose 53 minutes before the onset of tremor stagnation. Nevertheless, this lava

261 level rise corresponds in time with a sharp reduction in seismic tremor amplitudes (if not a

262 stagnation), which in that sense is typical. The overall higher lava levels in 2013-2015,

263 compared to 2010, permitted a view of most of the lake perimeter, thus allowing a count of the

264 number of spatter sources active through the day. Spattering phases consist of one or more

265 spattering sources in the lake; multiple spattering sources correspond to the periods with the

266 highest seismic tremor. Non-spattering phases correspond with a complete absence of spattering

267 sources in the lake. The surface crust velocity was relatively steady through the day and did not

268 appear to consistently drop during tremor stagnation as it did in the 2010 events. This lack of

269 obvious change in surface velocity during non-spattering phases was confirmed by examining

270 several dozen other events through 2013 and 2015.

271

272 During 2013 and up to the time of writing in early 2015, lake surface migration was normally

273 from its upwelling area at the north margin towards the south margin where it downwelled. A

274 spatter source was common at the southeast margin of the lake during spattering phases. During

275 spattering, the surface crust would be locally drawn towards the spatter sources, with crust 
276 seeming to "plunge" into the spattering area. Rockfalls which impacted the lake at the margin

277 often initiated spattering phases by triggering minor spattering at the point of impact that grew

278 into a large sustained spatter source. Typically, these spatter sources would migrate along the

279 margin towards the south, presumably carried by the prevailing circulation (akin to the

280 "traveling" fountains of early Halema'uma'u (Perret, 1913) and in the East Rift Zone in 2007

281 (Patrick et al., 2011a); Supplementary Video 3). Occasional spattering that appeared near the 282 center of the lake, not triggered by rockfalls, would also be carried south in the current.

284 4.5. Relation with rockfalls

286 An important aspect of the gas pistoning in 2010-2015 was the common association with 287 rockfalls from the Overlook crater walls (Fig. 8). Based on webcam and visual observations, 288 rockfalls often terminated or, more rarely, initiated gas piston events. Small rockfalls (even 289 single rocks $<1 \mathrm{~m}$ diameter) often pierced the surface of the lava lake during a rise or plateau 290 phase. Weak spattering would begin at the impact point and gradually expand in size and 291 intensity, further disrupting the crust and causing the lake surface to undulate as the level 292 dropped, terminating the gas piston event and restarting a spattering phase. This continuity of 293 increasing spattering intensity at the puncture point indicated that the rockfalls triggered these 294 fall phases, and were not merely coincidences. This observation is similar to that in Swanson et 295 al. (1979), who found that they could trigger spattering and gas piston fall phases by piercing the 296 lava surface with thrown objects. More rarely, larger rockfalls would impact the lake, triggering 297 a very long period seismic signal (Orr et al. 2013), followed within minutes by the onset of a rise 298 phase and cessation of spattering (Fig. 8a-c). 
300 We also observed an apparent correlation with longer term lava level drop and non-spattering

301 activity. During summit deflation, the overall lava level would drop; more frequent small

302 rockfalls were common during low lava levels as the veneer of juvenile lava adhered onto the

303 crater walls detached and fell into the lake. At these times, non-spattering phases seemed to be

304 more common (Fig. 8d), producing short-term gas-driven lava level fluctuations superimposed

305 on the longer term lava level change (Patrick et al. 2015b) that relates to ground tilt (Fig. 8e).

306

\section{5. Discussion}

309 5.1. Gas pistoning: shallowly or deeply sourced?

311 Published explanations for gas piston behavior include 1) shallow gas accumulation, trapped by

312 the crust or within a foam (e.g., Swanson et al., 1979, Patrick et al., 2010; Orr and Rea, 2012), 2)

313 deeply sourced gas slugs (e.g., Jaupart and Vergniolle, 1988), and 3) dynamic pressure balance

314 (Whitham et al., 2006). Shallow gas accumulation, at or near the surface of the lava lake,

315 appears to drive the gas piston events in this study based on the following observations:

316 1) Seismic and infrasonic tremor, gas emissions and visual observations are consistent with a

317 "trapping” process. Figures 3 and 7 show that rise phases begin with an abrupt decrease in

318 seismic and infrasonic tremor amplitudes, and gas emissions (Fig. 5,7) relative to steady

319 background levels. Likewise, these measurements increase dramatically above background

320 levels during fall phases. The instantaneous and inverse correspondence between outgassing 
and lava level implies a shallow build-up and release process, rather than an injection of

322 additional gas (i.e., a gas slug) from depth.

323 2) Changes in $\mathrm{SO}_{2} / \mathrm{CO}_{2}$ ratio exclude deep $\mathrm{CO}_{2}$-rich gas: The FTIR data show a decrease in

$324 \mathrm{CO}_{2}$ relative to $\mathrm{SO}_{2}$ during fall phases (Fig. 6c), consistent with a process dominated by $\mathrm{SO}_{2}$

325 and $\mathrm{H}_{2} \mathrm{O}$ exsolution originating at depths of several hundred meters or less (Appendix). The

326 data do not show evidence of $\mathrm{CO}_{2}$ enrichment relative to the other gases, as would be found

327 with deeply sourced gas slugs (Edmonds and Gerlach, 2007; Burton et al., 2007).

328 3) Triggering by rockfalls suggests a shallow process: Small rockfalls triggering the fall phases

329 (termination of gas pistons) suggest that gas is accumulating just beneath the surface during

330 gas piston events. Likewise, their occasional triggering by rockfalls also suggests a shallow

$331 \quad$ process.

332 4) Spattering activity is shallowly rooted in the lake: The observations that spattering a)

333 migrates with the lake current, b) is not tied to the upwelling area in the north portion of the

334 lake, and c) can be triggered by small rockfalls, suggest that spattering in general is shallowly

335 rooted in the upper portions of the lake.

336 5) The gas-pistoning in the 2007 East Rift Zone perched lava channel shows that the shallow

337 gas accumulation model can drive gas piston activity, providing a clear precedent for the

338 shallow accumulation model (Patrick et al., 2011a).

340 We envision that shallow gas accumulation occurs near the top of the lava lake (depths of several

341 tens of meters or less), well above the depths of significant $\mathrm{SO}_{2}$ and $\mathrm{H}_{2} \mathrm{O}$ exsolution (Gerlach,

342 1986; Appendix). We therefore expect that $\mathrm{SO}_{2}$ and $\mathrm{H}_{2} \mathrm{O}$-rich bubbles rise upwards continuously

343 from their exsolution depths of several hundred meters into the shallow portions of the lake. 
344 Spattering normally releases this gas from the lake, but gas pistoning occurs when this rising $\mathrm{SO}_{2}$

345 and $\mathrm{H}_{2} \mathrm{O}$-rich gas accumulates near the surface. The role of exsolution at very shallow (tens of

346 meters) depths appears to be minor, as shown by the increase in $\mathrm{SO}_{2}$ relative to $\mathrm{HCl}$ at the onset

347 of fall phases (Appendix).

349 The gas slug model is not consistent with our observations for several of the reasons above. In

350 addition, the rise phases during 2010 lasted tens of minutes to over an hour, which is

351 unrealistically long for the terminal ascent phase of a slug (James et al., 2008). Second, the lava

352 level plateaus (Fig. 3) would require the slug to pause at a shallow level for the duration of the

353 plateau phase (several hours) prior to bursting and lava level fall. Third, the volume change of

354 the lake during gas pistons in 2010 was $\sim 10^{5} \mathrm{~m}^{3}$, which is several thousand times larger than the

355 estimated slug volumes at Stromboli (Ripepe and Marchetti, 2002), and seem implausibly large

356 for a gas slug. Fourth, the episodically high $\mathrm{SO}_{2} / \mathrm{CO}_{2}$ and $\mathrm{H}_{2} \mathrm{O} / \mathrm{CO}_{2}$ ratios during fall phases are

357 consistent with a process dominated by $\mathrm{SO}_{2}$ or $\mathrm{H}_{2} \mathrm{O}$ rather than a very deep one driven by $\mathrm{CO}_{2}$,

358 and is contrary to the $\mathrm{CO}_{2}$ enrichment reported for deeply sourced gas slugs (Edmonds and

359 Gerlach, 2007; Burton et al., 2007).

361 The dynamic pressure balance model (Witham et al., 2006) does not apply to the Halema'uma $u$

362 gas piston events in this study, because the gas release timing predicted by that model is opposite

363 to what is observed. In that model, increased gas flow occurs during the rise phase, and gas flow

364 is inhibited during the fall phase. In contrast, $\mathrm{SO}_{2}$ concentration data and webcam observations

365 show the rise phase at Halema'uma'u represents a pronounced decrease in outgassing, plume

366 vigor and spattering (Fig. 4), and the fall phase ushers in an increase in these parameters. 
$368 \quad$ 5.2. Outgassing regimes

370 Based on our observations of lava lake activity at Halema'uma'u, we identify two dominant

371 styles of outgassing from the lake (Fig. 9): 1) passive outgassing and 2) spattering. Passive

372 outgassing consists of many small bubbles releasing gas through the lake surface (at the

373 incandescent cracks and through points in the crustal plates) in a scattered fashion (Fig. 10).

374 Passive outgassing accounts for roughly a third of the total $\mathrm{SO}_{2}$ emission during normal tremor

375 periods. Spattering consists of a train of larger bubbles bursting at the margin of the lake, feeding

376 one or more spattering sources. Spattering is responsible for roughly two-thirds of $\mathrm{SO}_{2}$

377 emissions during normal tremor periods. A third outgassing style was associated with occasional 378 small slug bursts at the upwelling area (Orr et al., 2014), though this is presumably a very minor 379 contributor.

381 At any given time, overall lake behavior is determined by the dominance of the above outgassing 382 styles, and can belong to one of two regimes: a spattering regime, and a non-spattering regime.

383 During spattering regimes, outgassing consists of both 1) passive outgassing and 2) spattering 384 styles. Seismic and infrasonic tremor and total gas output are at normal levels, and the plume is 385 robust. Non-spattering regimes exhibit only passive outgassing, where the lake is quiet and 386 tremor amplitudes are low, and the lava lake level rises due to gas pistoning. The gas emissions 387 rates are low $\left(\mathrm{SO}_{2}\right.$ is roughly a third of that during spattering regimes), and the plume is thin and 388 wispy. Lava upwelling and surface crust migration continues during non-spattering regimes. In 
389 the absence of spattering during non-spattering phases, gas accumulates at the top of the lake,

390 leading to gas pistoning.

391

392 Nadeau et al. (2014) presented data suggesting an apparent gas "deficit" exists with respect to $393 \mathrm{SO}_{2}$ during non-spattering phases. It appeared that the pulse of gas released during the brief

394 vigorous spattering that terminated non-spattering phases (and presumably represented the 395 accumulated gas driving the gas piston) was insufficient to account for the total gas mass that 396 would be expected for that time interval based on emission rates during spattering phases. Given

397 the uncertainties in their data, they were not able to establish this deficit conclusively. Our lava

398 level data confirm this deficit. The lava level plateau common to gas piston events indicates that 399 net gas accumulation only occurs during the rise phase, but ceases during the plateau phase. The 400 plateau phase represents equilibrium between a) gas supply beneath the surface and b) outflux 401 from the surface - albeit at an overall outgassing rate much lower than that during spattering 402 regimes $\left(\mathrm{SO}_{2}\right.$ emission roughly a third of that during spattering).

404 5.3. Gas pistoning controls

406 Our data show convincingly that gas pistoning and non-spattering behavior are driven by gas 407 accumulation near the top of the lava lake, but the precise mechanism which modulates this 408 process is more difficult to constrain. We favor a general model which follows that of Orr and 409 Rea (2012), in which the gas pistoning represents the growth and failure of a shallow foam layer 410 at the top of the lake (Fig. 10), irrespective of a surface crust. We envision that a continuous 411 supply of $\mathrm{SO}_{2}$ - and $\mathrm{H}_{2} \mathrm{O}$-rich gas bubbles rises upwards from exsolution depths of several 
412 hundred meters or less. Non-spattering phases (i.e. the rise and plateau phases of gas pistoning)

413 occur when these rising bubbles accumulate near the top of the lake, creating a foam. The foam

414 evolves through time as drainage, diffusion and bubble coalescence ensue (Mangan and

415 Cashman, 1996; Orr and Rea, 2012), and may mature to a porosity and/or permeability state that 416 encourages large scale coalescence, gas decoupling and spattering, which collapses the foam.

418 Rockfalls trigger some, but not all, spattering phases. In the absence of rockfalls, what triggers 419 spattering phases and foam collapse? Carbone et al. (2013) showed that the depth-averaged bulk 420 density of the Halema'uma'u lake was quite low (about $950 \mathrm{~kg} \mathrm{~m}^{-3}$ ), equivalent to a depth421 averaged porosity of $62 \%$. If we assume that gas accumulation is focused near the upper surface 422 of the lake, this implies that the porosity in the upper portions of the lake could be much higher 423 than $62 \%$. Previous studies have highlighted that significant permeability is achieved at 424 porosities $>70 \%$ (e.g., Mangan and Cashman, 1996; Namiki and Manga, 2008). The upper 425 portions of the lake may therefore often be close to such a threshold, if one exists, with gas 426 pistoning and spattering/non-spattering transitions representing the lake fluctuating around the

427 threshold. Spattering might be triggered by the foam intrinsically evolving to a state of sufficient 428 porosity and/or permeability that large scale gas decoupling ensues and the foam breaks down 429 (Orr and Rea, 2012). Small rockfalls are an extrinsic mechanism to increase local permeability. 430

431 What triggers non-spattering phases and foam formation? The observation that large rockfalls 432 seem to trigger some gas piston events may suggest that impact nucleation could be one trigger 433 for foam formation (Carey et al. 2012). However, most gas piston events are not preceded by 434 large rockfalls. Besides impact nucleation, an alternate trigger may relate to the observation that 
435 non-spattering phases also appear to be more common during summit deflation phases, when

436 baseline lava level drop encourages more frequent small rockfalls into the lake (Fig. 8d,e). Both

437 large and small rockfalls tend to trigger intense spattering (i.e., excess outgassing), and this may

438 exhume sufficient gas from the upper portion of the lake that the shallow lake porosity drops to a

439 less permeable state, hindering coalescence and decoupling and shutting off spattering - building

440 a foam instead.

441

442 What explains the lava level plateau? Plateaus occur during non-spattering regimes, when gas

443 release from the lake is limited to passive outgassing. The steady lava level implies a stable

444 foam thickness, maintaining a rough balance between the passive outgassing at the lake surface

445 and the supply of bubbles into the base of the foam. Foam stability depends on a number of

446 factors, including drainage, surface tension, bubble radius and gas velocity (Pilon et al. 2001).

447 The gas piston heights of 2010 (as much as $20 \mathrm{~m}$ ) vs. 2013-2015 (<5 m) suggest a large

448 difference in stable foam thickness for these periods, albeit roughly consistent within a given

449 time period. A coarse sampling of gas piston heights from 2012 to 2013 indicates that piston

450 heights dropped to a few meters after the lake's baseline lava level abruptly rose in early 2013,

451 leading to an enlargement of the lake surface area. We speculate that the enlargement of the lake

452 was responsible for the smaller gas piston amplitudes. A primary control on stable foam

453 thickness is superficial gas velocity, defined as gas volumetric flux $\left(\mathrm{m}^{3} / \mathrm{s}\right)$ divided by container

454 cross-sectional surface area $\left(\mathrm{m}^{2}\right)$ by Pilon et al. (2001), with a lower velocity resulting in a

455 thinner foam layer. Given that overall $\mathrm{SO}_{2}$ outgassing rates did not have an obvious trend

456 between 2010 and 2013, this suggests that the superficial gas velocity, by that definition, would

457 have decreased over this period with the increase in lake surface area. 
459 Why is there a gas deficit during non-spattering regimes? The plateau is linked to the gas deficit

460 suggested by Nadeau et al. (2014); the balanced outgassing and steady lava level occur in a 461 regime of significantly reduced overall outgassing rates, compared to spattering regimes. To 462 explain the deficit, either the supply of gas from the deeper system has slowed, or some gas that

463 has already entered the lake is circulated back into the deeper system due to the presence of foam 464 at the top of the lake. The reduced velocities during gas piston events in 2010 (Fig. 3) might 465 support the former mechanism, but 2013-2014 data do not show consistently lowered surface 466 velocities during gas piston events (Fig. 7). Instead, the 2014 data suggest a mechanism of gas 467 "recycling", shown to be viable by Carey et al. (2013), who found that bubbles that had entered 468 the lake were being carried back to a deeper level.

470 Why were surface velocities different in 2010 and 2013-2015? One possible explanation is lake 471 size. We have observed that surface crust velocity is determined, in part, by proximity to 472 spattering sources, with increased surface velocities closer to an active spattering source (nearby 473 surface crust plunges towards spattering areas). With the smaller lake in 2010, the surface 474 velocity may have been more strongly influenced by the presence or absence of a spatter source, 475 resulting in lowered surface velocities during non-spattering phases. In 2013-2015, the 476 relatively steady surface velocities throughout the spattering and non-spattering phases might 477 represent less sensitivity due to the larger lake area (and overall greater distances from the 478 spattering source), with 2013-2015 surface velocities more closely reflecting the deeper 479 convective motion of the lake. Another explanation for the difference in surface velocity 480 fluctuation may be due to the different gas piston heights. In 2010, the gas piston heights, which 
481 may correspond to the thickness of the shallow foam layer, were much higher than those in

482 2013-2015, and this thicker foam layer may have imparted a rheological resistance to surface

483 movement.

484

485 5.4. Comparison with other lava lakes

486

487 Cyclic activity appears to be common at persistent lava lakes. At Erta 'Ale, Harris et al. (2005)

488 described two modes of activity, "sluggish" and "vigorous", each lasting tens of minutes to

489 several hours. Sluggish behavior consisted of low velocities and cooler crust with fewer

490 incandescent cracks. Vigorous activity had higher velocities and a crust more disrupted by

491 incandescent cracks. They attributed these modes of activity to changing convective regimes in

492 the lake, but could not determine if the ultimate cause was shallow (internal to the lake) or more

493 deeply (externally) sourced. Spampinato et al. (2008) tracked fluctuations at Erta 'Ale and

494 explained them as having a deep source, based on the modeling of Whitham et al. (2006). The

495 lava lake at Erebus exhibits fluctuations in surface velocity, radiative heat output and $\mathrm{SO}_{2} / \mathrm{CO}_{2}$

496 ratio (Oppenheimer et al., 2009; Peters et al. 2014), which is explained by pulses of $\mathrm{H}_{2} \mathrm{O}$ - and

$497 \mathrm{SO}_{2}$-rich magma from the deeper magmatic system into the lake. Spampinato et al. (2013)

498 showed that the Nyiragongo lava lake had oscillations in lava lake level with a change of a few

499 meters over several days, attributed to variations in the deep system based on the precedent of

500 previous studies such as Whitham et al. (2006) and Oppenheimer et al. (2009).

501

502 The behavior we observe in Halema'uma' $u$ is distinct from that described by previous studies in

503 two major aspects. First, the Halema'uma'u lake exhibits more abrupt transitions than those at 
504 Erta 'Ale or Erebus. The Halema'uma'u activity we show here can be considered an end-

505 member on a transition scale from gradual (Erebus), to moderately abrupt (Erta 'Ale) to

506 extremely abrupt (this study). The abrupt—and extreme — changes at Halema'uma'u result in a

507 kind of binary outgassing behavior, with the lake switching between full (spattering regime) and

508 dramatically subdued (non-spattering regime) outgassing. Second, the changes at Erta 'Ale,

509 Erebus and Nyiragongo, are attributed to deeply-sourced, conduit-driven, processes that are

510 external to the lakes themselves. In contrast, we show that changes in lake behavior at

511 Halema'uma'u are consistent with shallow processes that are internal to the lake.

512

513 Our study highlights the potential for a lava lake to modulate its own outgassing independent of

514 deeper processes. Lake size, and the resulting lava residence time in the lake, is a possible

515 explanation for this difference - with an area of roughly $25,000 \mathrm{~m}^{2}$, Halema'uma'u is the

516 second largest lava lake on Earth, second only to Nyiragongo (Spampinato et al., 2013). Given

517 its depth (>100 $\mathrm{m}$ in 2011, Carbone et al., 2013), the lake represents a large repository of gas-

518 charged lava, in which gas is released in an unsteady, episodic manner. By reconciling the

519 magma supply rate with the estimated lake volume, Oppenheimer et al. (2009) estimated a

520 residence time for magma in the Erebus lava lake at around four hours. For Halema'uma'u,

521 reconciling the rough magma supply rate $\left(3 \mathrm{~m}^{3} / \mathrm{s}\right.$ dense rock, Edmonds et al., 2013) with the

522 lake's total lava mass (volume of $2.5 \times 10^{6} \mathrm{~m}^{3}$ at a density of $1000 \mathrm{~kg} / \mathrm{m}^{3}$, Carbone et al., 2013),

523 we estimate an average lava residence time of about four days. This internal "momentum" may

524 allow for lake circulation and outgassing cycles which are independent, on short timescales, of

525 conduit processes.

526 
527 Finally, seismic and infrasonic tremor amplitudes closely follow trends in outgassing, suggesting

528 that tremor is a good proxy for gas emission rates at Halema 'uma 'u (also shown by Nadeau et al.

529 2014). At Stromboli Volcano, tremor has been tied to bubble bursting at the lava free surface

530 (Ripepe et al. 1996), and our data indicate that the tremor at Halema'uma'u reflects spattering

531 intensity on the lake surface. This follows other recent studies that demonstrate tremor can be a

532 useful gauge for outgassing behavior at basaltic volcanoes (Nadeau et al., 2011; Palma et al.,

533 2008, Fee et al., 2010).

534

\section{Conclusions}

537 Cycles of lava level rise and fall (gas piston events), associated with tremor, lake surface 538 velocities, and outgassing levels, have been observed at Halema'uma'u since mid-2008, We use 539 multidisciplinary data to characterize the activity in 2010-2015, and reach the following 540 conclusions:

542 1) The lava lake abruptly switches between "spattering" and "non-spattering" regimes.

543 Spattering phases consist of both spattering and passive outgassing from the lake, as well as 544 elevated tremor and a vigorous outgassing plume. Non-spattering phases are associated with 545 only passive outgassing from the lake (no spattering), with greatly reduced tremor and a 546 weak outgassing plume. Non-spattering phases last several hours and correspond with the 547 lava lake level abruptly rising, in some cases $20 \mathrm{~m}$, in a process called "gas pistoning". 
2) Gas pistoning (non-spattering) is caused by the accumulation of gas near the top surface of the lava lake, perhaps as a shallow foam. Our data show that gas pistoning at Halema'uma'u

3) We speculate that the gas pistoning might be controlled by time-varying porosity and/or permeability in the upper portions of the lava lake, which may modulate bubble coalescence and spattering.

4) An outgassing "deficit" exists during non-spattering phases, and may imply gas "recycling"

5) Seismic and infrasonic tremor amplitudes closely mimic outgassing trends, probably due to the intensity of spattering on the lava surface, suggesting that seismic and infrasonic tremor

6) Outgassing fluctuations in Halema'uma' $u$ are controlled by shallow processes, internal to the lake itself, in contrast with other lakes where cyclic activity is thought to be more deeply driven.

564 Our study illustrates the value of multidisciplinary monitoring for constraining the diverse 565 aspects of open-vent activity. In particular, camera observations are vital for measuring activity on the surface (Orr and Rea, 2012), and complement the geophysical data that track changes

567 below (seismic) and above (infrasound) the ground. The gas piston events, and spattering/non568 spattering regimes, highlight the complex and unsteady nature of outgassing from basaltic 569 systems. These observations should serve as a valuable basis for quantitative modeling of gas 570 segregation and loss at lava lakes and other open-vent basaltic systems. 


\section{Acknowledgements}

574 HVO staff assisted in the collection of the data in this study. This work was supported by the 575 U.S. Geological Survey Volcano Science Center. Lev was supported by NSF grant EAR576 1348022. Fee was supported by the University of Alaska Fairbanks Geophysical Institute.

577 Reviews by M. James, J. Lyons and two anonymous reviewers improved the manuscript 578 substantially. Any use of trade, firm, or product names is for descriptive purposes only and does 579 not imply endorsement by the U.S. Government.

\section{References}

582

583 Burton, M., Allard, P., Mure, F., La Spina, A., 2007. Magmatic gas composition reveals the 584 source depth of slug-driven Strombolian explosive activity. Science 317, 227-230.

586 Carbone, D., Poland, M.P., Patrick, M.R., Orr, T.R., 2013. Continuous gravity measurements 587 reveal a low-density lava lake at Kīlauea Volcano, Hawai'i. Earth Planet. Sci. Lett. 376, 178588185.

590 Carey, R.J., Manga, M., Degruyter, W., Swanson, D., Houghton, B., Orr, T., Patrick, M., 2012, 591 Externally triggered renewed bubble nucleation in basaltic magma: The 12 October 2008 592 eruption at Halema‘uma‘u Overlook vent, Kīlauea Volcano, Hawai'i, USA. J. Geophys. Res. B, 593 Solid Earth, 117, B11202. 
595 Carey, R.J., Manga, M., Degruyter, W., Gonnerman, H., Swanson, D., Houghton, B., Orr, T., 596 Patrick, M., 2013. Convection in a volcanic conduit recorded by bubbles. Geology 41, 395-398. 597 doi:10.1130/G33685.1

598

599 Chouet, B., Dawson, P., 2015, Seismic source dynamics of gas-piston activity at Kilauea

600 Volcano, Hawaì. Journal of Geophysical Research Solid Earth 120, 2525-2560, 601 doi:10.1002/2014JB011789

602

603 Edmonds, M., Gerlach, T.M., 2007. Vapor segregation and loss in basaltic melts. Geology 35, $604 \quad 751-754$.

605

606 Edmonds, M., Sides, I.R., Swanson, D.A., Werner, C., Martin, R.S., Mather, T.A., Herd, R.A., 607 Jones, R.L., Mead, M.I., Sawyer, G., Roberts, T.J., Sutton, A.J., Elias, T., 2013. Magma storage, 608 transport and degassing during the 2008-10 summit eruption at Kîlauea Volcano, Hawai'i. 609 Geochimica et Cosmochimica Acta 123, 284-301.

610

611 Elias, T., Sutton, A.J., 2012. Sulfur dioxide emission rates from Kīlauea volcano, Hawai ‘i 2007612 2010. U.S. Geological Survey Open File Report 2012-1107, 37 pp.

614 Fee, D., Garces, M., 2007. Infrasonic tremor in the diffraction zone. Geophys. Res. Lett. 34, 615 L16826, doi: 10.1029/2007GL030616.

616 
617 Fee, D., Garces, M., Patrick, M., Chouet, B., Dawson, P., 2010. Infrasonic harmonic tremor and 618 degassing bursts from Halema‘uma‘u Crater, Kīlauea Volcano, Hawai‘i. J. Geophys. Res. 155, 619 B11316.

620

621 Gerlach, T.M., 1986. Exsolution of $\mathrm{H}_{2} \mathrm{O}, \mathrm{CO}_{2}$, and $\mathrm{S}$ during eruptive episodes at Kilauea 622 Volcano, Hawaii. J. Geophys. Res. 91, 12177-12185.

623

624 Harris, A.J.L., Carniel, R., Jones, J., 2005. Identification of variable convective regimes at Erta 625 Ale lava lake. J. Volcanol. Geotherm. Res. 142, 207-223.

626

627 Houghton, B., Orr, T., Taddeucci, J., Gonnermann, H., Scarlato, P., Del Bello, E., Carey, R., 628 Patrick, M., 2014. The dynamics of prolonged low fountaining behavior at Halemaumau, 629 Kilauea, in December 2013. Abstract V23C-4803 presented at Fall AGU meeting, San Francisco, 630 15-19 Dec.

632 Jaupart, C., Vergniolle, S., 1988. Laboratory models of Hawaiian and Strombolian eruptions. 633 Nature 331, 58-60.

634

635 James, M.R., Lane, S.J., Corder, S.B., 2008. Modelling the rapid near-surface expansion of gas 636 slugs in low-viscosity magmas. In: Lane, S.J., and Gilbert, J.S. (eds) Fluid motions in volcanic 637 conduits: a source of seismic and acoustic signals. Geol Soc London Special Pub 207, 147-167. 
639 Lev, E., Spiegelman, M., Wysocki, R.J., Karson, J.A., 2012. Investigating lava flow rheology

640 using video analysis and numerical analysis. J. Volcanol. Geotherm. Res. 247, 62-73.

641

642 Mangan, M.T., Cashman, K.V., 1996, The structure of basaltic scoria and reticulate and

643 inferences for vesiculation, foam formation, and fragmentation in lava fountains. Journal of

644 Volcanology and Geothermal Research 73, 1-18.

645

646 Nadeau, P.A., Palma, J.L., Waite, G.P., 2011. Linking volcanic tremor, degassing and eruption

647 dynamics via $\mathrm{SO}_{2}$ imaging. Geophys. Res. Lett. 38, L01304, doi:10.1029/2010GL045820

649 Nadeau, P.A., Werner, C.A., Waite, G.P., Carn, S.A., Brewer, I.D., Elias, T., Sutton, A.J., Kern, 650 C. 2014. Using $\mathrm{SO}_{2}$ camera imagery and seismicity to examine degassing and gas accumulation 651 at Kīlauea Volcano, May 2010. J. Volcanol. Geotherm. Res., published online: 652 doi:10.1016/j.jvolgeores.2014.12.005.

654 Namiki, A., Manga, M., 2008, Transition between fragmentation and permeable outgassing of 655 low viscosity magmas. Journal of Volcanology and Geothermal Research 169, 48-60.

657 Oppenheimer, C, Yirgu, G., 2002. Thermal imaging of an active lava lake: Erta 'Ale, Ethiopia. 658 Int. J. Remote Sens. 23, 4777-4782.

659

660 Oppenheimer, C., Lomakina, A.S., Kyle, P.R., Kingsbury, N.G., Boichu, M., 2009. Pulsatory 661 magma supply to a phonolite lava lake. Earth Planet. Sci. Lett. 284, 392-398. 
663 Orr, T.R., Rea, J.C., 2012. Time-lapse camera observations of gas piston activity at $\mathrm{Pu}^{`} \mathrm{u}{ }^{`} \overline{\mathrm{O}}^{`} \overline{\mathrm{o}}$, 664 Kīlauea volcano, Hawai'i. Bull. Volcanol. 74, 2353-2362.

666 Orr, T.R., Thelan, W., Patrick, M.R., Swanson, D.A., Wilson, D.C., 2013. Explosive eruptions 667 triggered by rockfalls at Kīlauea Volcano, Hawai‘i. Geology 41, 207-210.

669 Orr, T.R., Houghton, B.F., Taddeucci, J., Del Bello, E., Scarlato, P., Patrick, M.R., 2014. The 670 bubble's wake: localized rebound of Kīlauea's summit lava lake following minor bubble bursts, 671 Abstract V41D-05 presented at 2014 Fall Meeting, AGU, San Francisco, Calif., 15-19 Dec.

673 Orr, T.R., Poland, M.P., Patrick, M.R., Thelen, W.A., Sutton, J., Elias, T., Thornber, C.T. 674 Parcheta, C., Wooten, K.M., 2015. Kīlauea’s 5-9 March 2011 Kamoamoa fissure eruption and its 675 relation to $30+$ years of activity from $\mathrm{Pu}^{‘} \mathrm{u}$ ' $\overline{\mathrm{O}}^{`} \mathrm{o}$. In: Carey, R., Poland, M., Cayol, V., Weis, D. 676 (eds) Hawaiian Volcanism: From Source to Surface, AGU Geophysical Monograph Series.

678 Palma, J.L., Calder, E.S., Basualto, D., Blake, S., Rothery, D., 2008. Correlations between SO2 679 flux, seismicity and outgassing activity at the open vent of Villarrica volcano, Chile. J Geophys. 680 Res. 113, B10201.

682 Patrick, M.R., Wilson, D., Fee, D., Orr, T., Swanson, D., Sutton, A.J., Elias, T., 2008. Gas683 pistoning associated with the 2008 summit eruption of Kîlauea Volcano, Hawai' $\mathrm{i}$, Abstract 684 V51E-2082 presented at 2008 Fall Meeting, AGU, San Francisco, Calif., 15-19 Dec. 
686 Patrick, M.R., Orr, T.R., Wilson, D., Sutton, A.J., Elias, T., Fee, D., Nadeau, P.A., 2010.

687 Evidence for gas accumulation beneath the surface crust driving cyclic rise and fall of the lava 688 surface at Halema'uma'u, Kîlauea Volcano. Abstract V21C-2339 presented at 2010 Fall 689 Meeting, AGU, San Francisco, Calif., 13-17 Dec.

690

691 Patrick, M.R., Orr, T., Wilson, D., Dow, D., Freeman, R., 2011a. Cyclic spattering, seismic 692 tremor, and surface fluctuation within a perched lava channel, Kīlauea Volcano. Bull. Volcanol. $69373,1179-1186$.

694

695 Patrick, M.R., Wilson, D., Fee, D., Orr, T., Swanson, D., 2011b. Shallow degassing events as a 696 trigger for very-long-period seismicity at Kîlauea Volcano, Hawai'i. Bull. Volcanol. 73, 1179697 1186, doi:10.1007/s00445-011-0475-y

698

699 Patrick, M.R., Orr, T., Sutton, A.J., Elias, T., Swanson, D., 2013. The first five years of 700 Kīlauea's summit eruption in Halema‘uma‘u, 2008-2013. US Geological Survey Fact Sheet $701 \quad 2013-3116$.

702

703 Patrick, M.R., Orr, T., Lee, L., Antolik, L., Kamibayashi, K., 2014. Continuous monitoring of 704 Hawaiian volcanoes with thermal cameras. J. Appl. Volcanol. 3, 1.

705 
706 Patrick, M.R., Orr, T., Lee, L., Moniz, C., 2015a. A multipurpose camera system for monitoring

707 Kīlauea Volcano, Hawai ‘i. U.S. Geological Survey Techniques and Methods, book 13, chap. A2

70825 p., doi: $10.3133 / \mathrm{tm} 13 \mathrm{~A} 2$

709

710 Patrick, M.R., Anderson, K.R., Poland, M.P., Orr, T.R., Swanson, D.A., 2015b, Lava lake level

711 as a gauge of magma reservoir pressure and eruptive hazard. Geology 43, 831-834.

712 doi:10.1130/G36896.1

713

714 Perret, F.A., 1913. The lava fountains of Kilauea. Am J Sci, $4^{\text {th }}$ ser, $35,139-148$.

715

716 Peters, N., Oppenheimer, C., Killingsworth, D.R., Frechette, J., Kyle, P., 2014. Correlation of

717 cycles in lava lake motion and degassing at Erebus Volcano, Antarctica. Geochem. Geophys.

718 Geosys. 15, doi:10.1002/2014GC005399

719

720 Pilon, L., Fedorov, A., Viskanta, R., 2001. Steady-state thickness of liquid-gas foams. Journal of

721 Colloid and Interface Science, 242, 425-436, doi:10.1006/jcis.2001.7802

722

723 Ripepe, M., Marchetti, E., 2002. Array tracking of infrasonic sources at Stromboli volcano.

724 Geophys. Res. Lett. 29, 2076, doi:10.1029/2002GL015452

725

726 Ripepe, M., Poggi, P., Braun, T., Gordeev, E. 1996. Infrasonic waves and volcanic tremor at

727 Stromboli. Geophys. Res. Lett. 23, 181-184.

728 
729 Spampinato, L., Oppenheimer, C., Calvari, S., Cannata, A., Montalto, P., 2008. Lava lake

730 surface characterization by thermal imaging: Erta 'Ale volcano (Ethiopia). Geochem. Geophys.

731 Geosys. 9, Q12008. doi:10.1029/2008GC002164.

732

733 Spampinato, L., Ganci, G., Hernandez, P.A., Calvo, D., Tedesco, D., Perez, N.M., Calvari, S.,

734 Del Negro, C., Yalire, M.M., 2013. Thermal insights into the dynamics of Nyiragongo lava lake

735 from ground and satellite measurements. J. Geophys. Res. 118, 5771-5784.

736

737 Swanson, D.A., Duffield, W.A., Jackson, D.B., Peterson, D.W., 1979. Chronological narrative of 738 the 1969-71 Mauna Ulu eruption of Kilauea volcano, Hawaii, U.S. Geological Survey 739 Professional Paper, 1056, 55 p.

740

741 Tilling, R.I., 1987. Fluctuations in surface height of active lava lakes during the 1972-1974

742 Mauna Ulu eruption, Kilauea volcano, Hawaii. J. Geophys. Res. 92, 13721-13730.

743

744 Vergniolle, S., Jaupart, C., 1990. Dynamics of degassing at Kilauea volcano, Hawaii. J. 745 Geophys. Res. 95, 2793-2809.

746

747 Wilson, D., Elias, T., Orr, T., Patrick, M., Sutton, A.J., Swanson, D., 2008. Small explosion from 748 new vent at Kîlauea's summit. EOS 89, 203.

750 Witham, F., Woods, A.W., Gladstone, C., 2006. An analogue experimental model of depth 751 fluctuations in lava lakes. Bull. Volcanol. 69, 51-56. 


\section{$753 \quad$ Figure captions}

755 Figure 1. Location of Kîlauea's summit eruption. (a) Halema'uma'u Crater is in the southwest 756 portion of Kîlauea's summit caldera. The lava lake is contained within the Overlook crater,

757 formed at the onset of the eruption in March 2008 and enlarging within the southeast portion of 758 Halema'uma'u. HVO marks the location of the Hawaiian Volcano Observatory. NPT and OTL 759 are seismic stations, yellow lines are roads. (b) Oblique aerial photograph of Halema'uma'u 760 Crater, looking west, on May 14, 2010. The Overlook crater is filled with thick fume, and emits

761 an outgassing plume that normally drifts southwest in the trade winds. The cameras and FTIR

762 were positioned at the Halema'uma'u (HMM) Overlook, $85 \mathrm{~m}$ above the rim of the Overlook

763 crater. (c) View of the Overlook crater from Halema'uma'u Crater rim, looking north, on June 1,

764 2010. The Overlook crater at this time was about $150 \mathrm{~m}$ wide, and the lava lake was about 140

$765 \mathrm{~m}$ below the Overlook crater rim (i.e., same distance below the floor of Halema'uma' $u$ ). (d)

766 View of the Overlook crater from Halema'uma'u Crater rim, looking northeast, on February 1, 767 2014, when the lake was roughly $50 \mathrm{~m}$ below the Overlook crater rim. The upwelling area is 768 along the north margin of the lake, whereas the downwelling is spread across the south margin. 769 At the southeast margin, a spattering source is commonly active and associated with the most 770 vigorous focus of downwelling.

772 Figure 2. About one month of activity in late 2010. (a) Lava level shows numerous gas piston

773 events superimposed upon a baseline lava level that began rising in mid-November. The

774 baseline lava level tracks summit ground tilt, indicating that the long-term lava level is closely 
775 tied to the pressure state of the summit magma reservoir (Patrick et al., 2015b). Each gas piston

776 event was associated with a drop (during rise and plateau phases) in (b) seismic tremor

777 amplitude, typically followed by a high-amplitude burst in tremor (during the fall phase).

779 Figure 3. An 18-hour period showing two gas piston events representative of those in late 2010.

780 (a-c) Thermal images showing lava lake level and surface activity. Lake is $\sim 80 \mathrm{~m}$ diameter. (d)

781 Lava level fluctuations during the two events, with each event consisting of a rise phase, a

782 plateau phase, and a fall phase. These gas piston events interrupt normal baseline lava level. (e-

783 f) The rise and plateau phases correspond to seismic and infrasonic tremor dropping to unusually

784 low amplitudes (tremor stagnation) compared to those during normal, baseline lava level. The

785 fall phases are associated with intense spattering, corresponding to bursts of seismic and

786 infrasonic tremor. (g) The rise phases correspond to a decrease in lake surface velocity, and the

787 plateau phases also appear to be associated with lower velocities. The fall phases are associated

788 with surges in the lake velocity, as the lava surface plunges towards the intensified spatter 789 source.

791 Figure 4. Variation of gas emission with tremor. (a-c) Example shown is from September 1, 792 2013, but similar behavior was observed throughout the study period. During periods of 793 unusually low tremor (tremor stagnation), the plume becomes weak, wispy and translucent, 794 suggesting decreased gas emissions. During normal behavior, the plume is more robust, 795 suggesting higher gas emissions. Red lines show time of images. (d) Comparison of seismic 796 tremor and $\mathrm{SO}_{2}$ emission rates for April 14, 2014, showing decreased emission during low 797 tremor (tremor stagnation). (e) Similar measurements during May 12, 2014. 
799 Figure 5. Several gas piston events in late November, 2010, exhibiting changes in (a) lava level,

800 (b) downwind $\mathrm{SO}_{2}$ concentration and (c) seismic tremor. Rise and plateau phases of a gas piston 801 event (and tremor stagnation) are associated with dramatically reduced downwind $\mathrm{SO}_{2}$ 802 concentration, implying that $\mathrm{SO}_{2}$ emission rates plummet during these phases. Brief peaks in $803 \mathrm{SO}_{2}$ concentration during the fall phases suggest that a burst in $\mathrm{SO}_{2}$ emission occurs at this time.

804 The close correspondence between $\mathrm{SO}_{2}$ concentration (and inferred $\mathrm{SO}_{2}$ emission) and seismic

805 tremor amplitude suggests that the tremor amplitude is closely correlated with surface outgassing 806 intensity.

807

808 Figure 6. Gas geochemistry for gas piston events on January 14, 2011. (a) Relative lava level

809 (b) RSAM and (c-e) gas ratios for several of the gas piston events. Elevated $\mathrm{SO}_{2} / \mathrm{CO}_{2}$ and $810 \mathrm{H}_{2} \mathrm{O} / \mathrm{CO}_{2}$ during fall phases contradicts a $\mathrm{CO}_{2}$-rich gas slug mechanism and indicates average 811 exsolution depths shallower than $1 \mathrm{~km}$. $\mathrm{SO}_{2} / \mathrm{HCl}$ is consistent with an average exsolution depth 812 greater than a few tens of meters.

813

814 Figure 7. Typical gas piston activity in 2013-2015. The lake fluctuated between spattering (a) 815 and non-spattering (b) regimes, with gas pistoning corresponding to non-spattering phases. Gas 816 piston activity in 2013-2015 had very minor lava level changes (c), and was better identified by 817 the changes in spattering (d) and seismic (e) and infrasonic (f) tremor. Unlike 2010 when 818 significant changes in surface crust velocity were associated with tremor stagnation (Fig. 3), 819 during 2013-2015 there was no obvious changes in velocity with gas piston events (g). The lake 820 is (a-b) is about $200 \mathrm{~m}$ long, and $50 \mathrm{~m}$ below the crater rim. 
822 Figure 8. Relation of rockfalls to gas pistoning. Rockfalls often impacted the lake, with larger 823 ones triggering a very long period seismic signal (a) and subsequent gas piston (non-spattering)

824 phase, shown by tremor stagnation (b) and lava level rise (c). During periods of summit 825 deflation, the overall lake level would drop (e), and this was often associated with more frequent 826 small collapses from the crater walls, and non-spattering phases (d, e) appeared to be more

827 frequent during these phases. The gas piston (non-spattering) lava level fluctuations were 828 superimposed on the broader baseline lava level change that correlated with tilt. RSAM is from 829 station NPT.

831 Figure 9. Summary of observations and interpretation. Gas piston cycles consist of elevated lava 832 level that may last for several hours, during which time seismic and infrasonic tremor 833 amplitudes, $\mathrm{SO}_{2}$ emission, plume optical thickness and nighttime glow at the crater drop to 834 unusually low levels (well below steady, background, levels). The $\mathrm{SO}_{2} / \mathrm{CO}_{2}$ ratio also drops 835 during high lava levels. During the fall phase of a gas piston, these indicators increase to 836 unusually high levels briefly, before dropping to normal, steady values. We interpret this 837 behavior in the context of outgassing behavior in the lake. During normal, steady behavior the 838 lake is in a spattering regime, and there is both passive outgassing and spattering. During the 839 elevated lava level of a gas piston cycle, the spattering shuts down and the lake is in a "non840 spattering" regime. The intense spattering associated with the lava fall phase returns the lake to 841 a spattering regime. 
843 Figure 10. Conceptual model for the gas piston and spattering/non-spattering regimes. During 844 spattering regimes, both passive outgassing (accounting for roughly a third of total $\mathrm{SO}_{2}$ 845 emissions) and spattering (roughly two-thirds of total $\mathrm{SO}_{2}$ emissions) are present, with spattering 846 representing the release of large, coalesced bubbles. During non-spattering regimes, the 847 shutdown of spattering is associated with gas accumulation at the top of the lake, perhaps as a 848 shallow foam, driving the rise of a gas piston. Only passive outgassing is present during non849 spattering regimes. The lack of spattering in this phase reduces total $\mathrm{SO}_{2}$ emission and also the 850 associated tremor and $\mathrm{SO}_{2} / \mathrm{CO}_{2}$ ratio.

851

852

853

854

855

856

857

858

859

860

861

862

863

864

865 
866 reduced RSAM (tremor stagnation). Several brief episodes (e.g., 17:18 and 20:14) of additional 867 spattering produce RSAM spikes, with the spattering carried by lake circulation towards the 868 normal spattering source location. A large episode of increased spattering around 05:50 869 produces a brief reversal in flow direction, and precedes the subsequent non-spattering phase. 

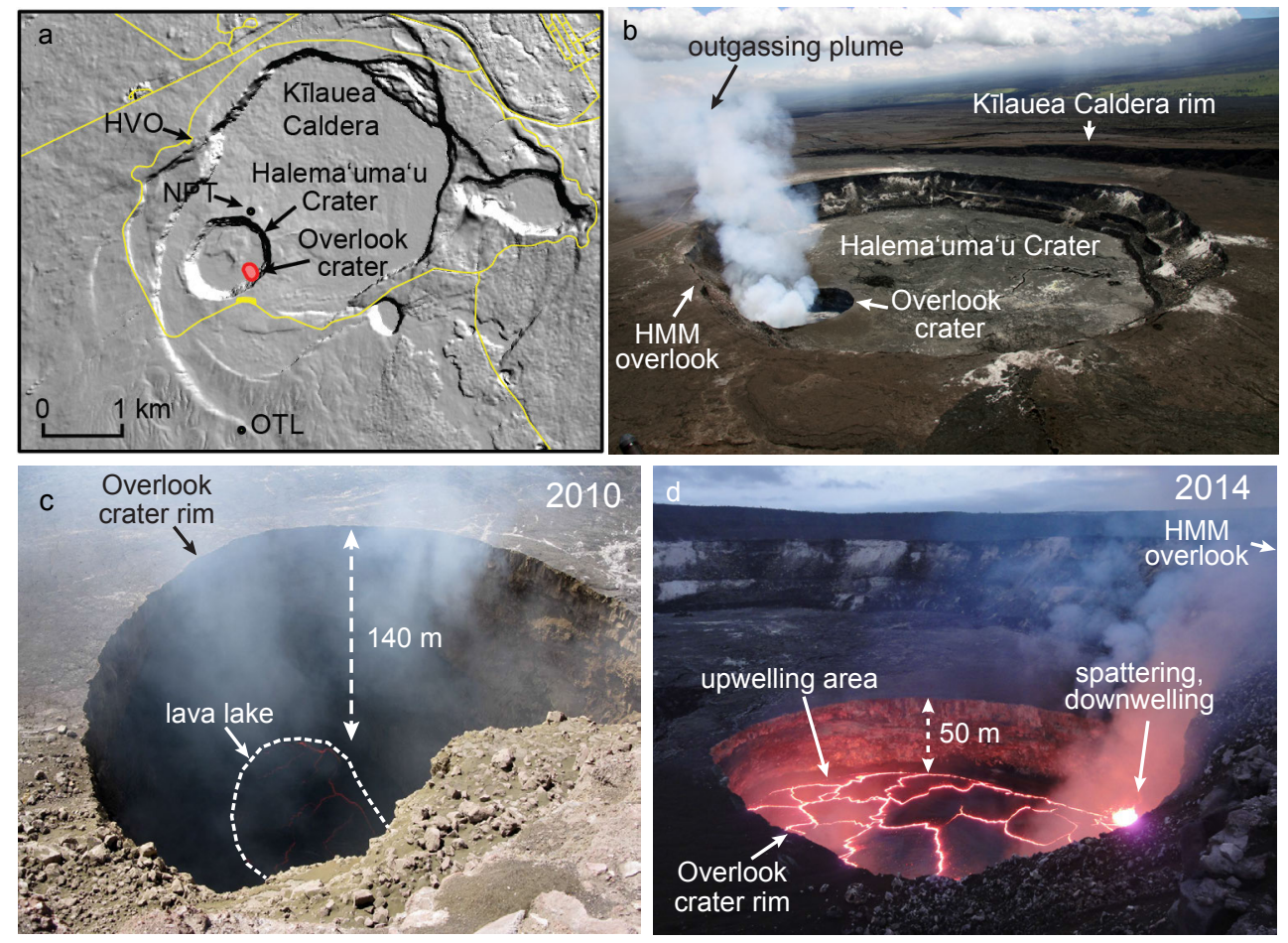

\section{Figure 1}




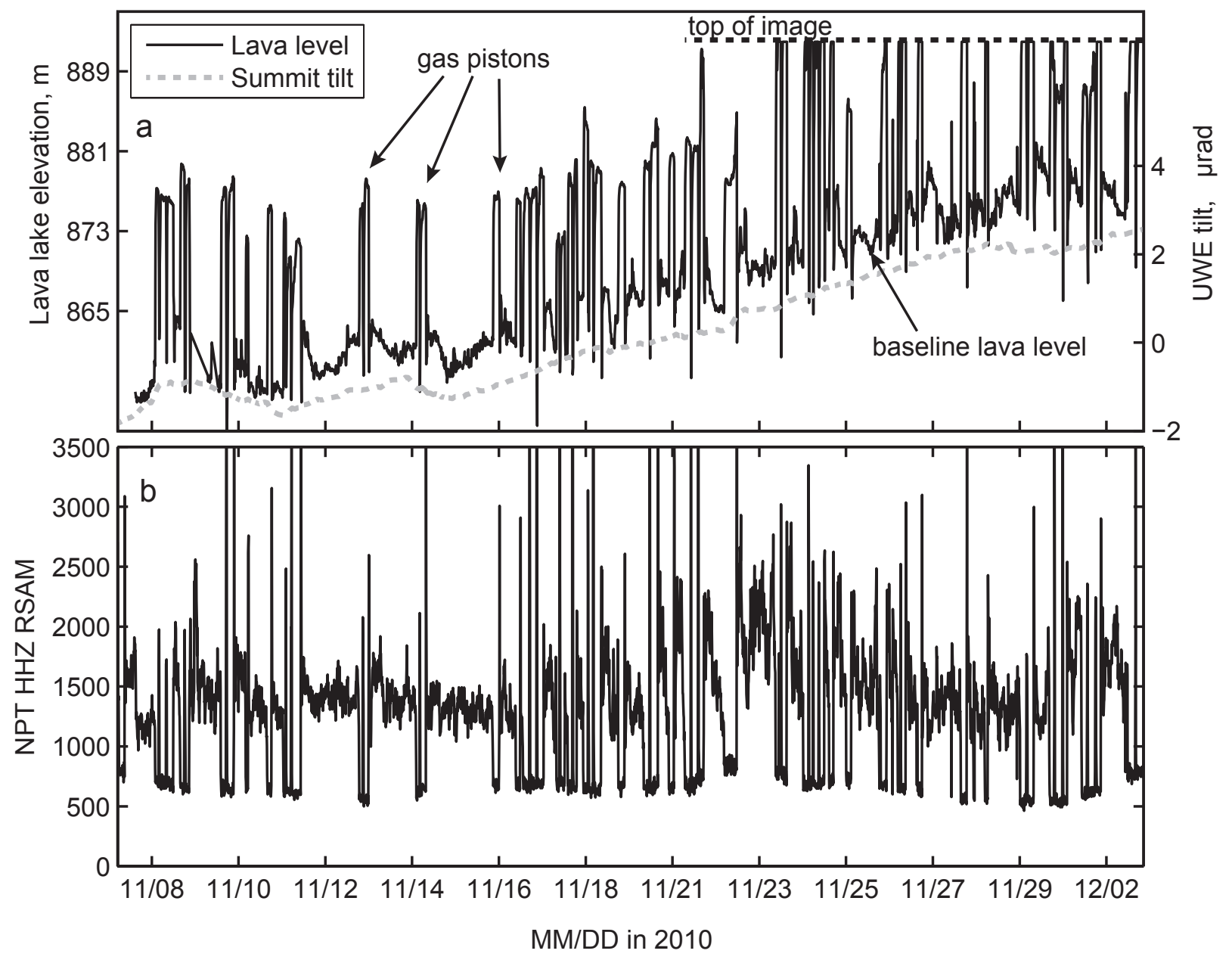

Figure 2 


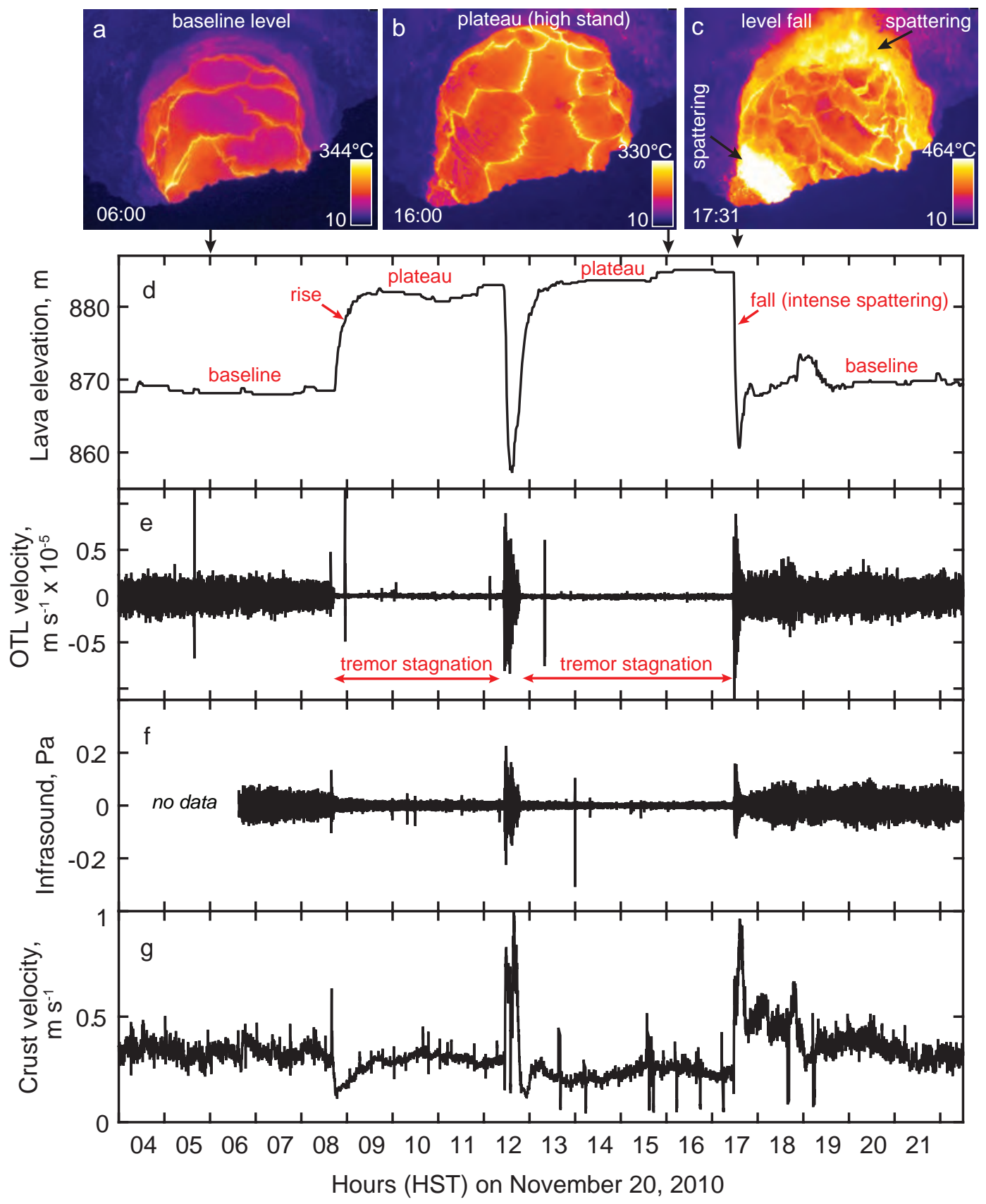

Figure 3 

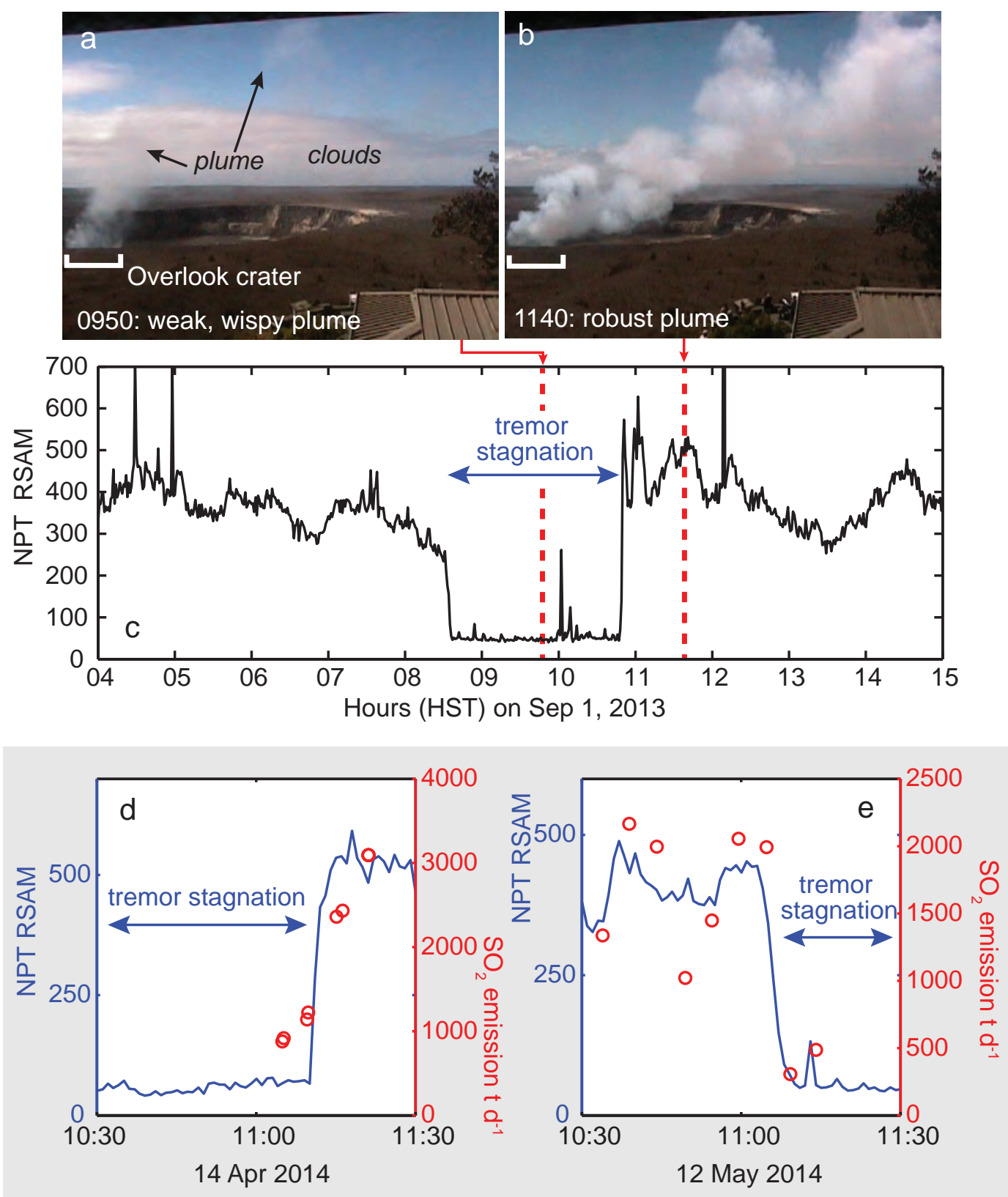

Figure 4 

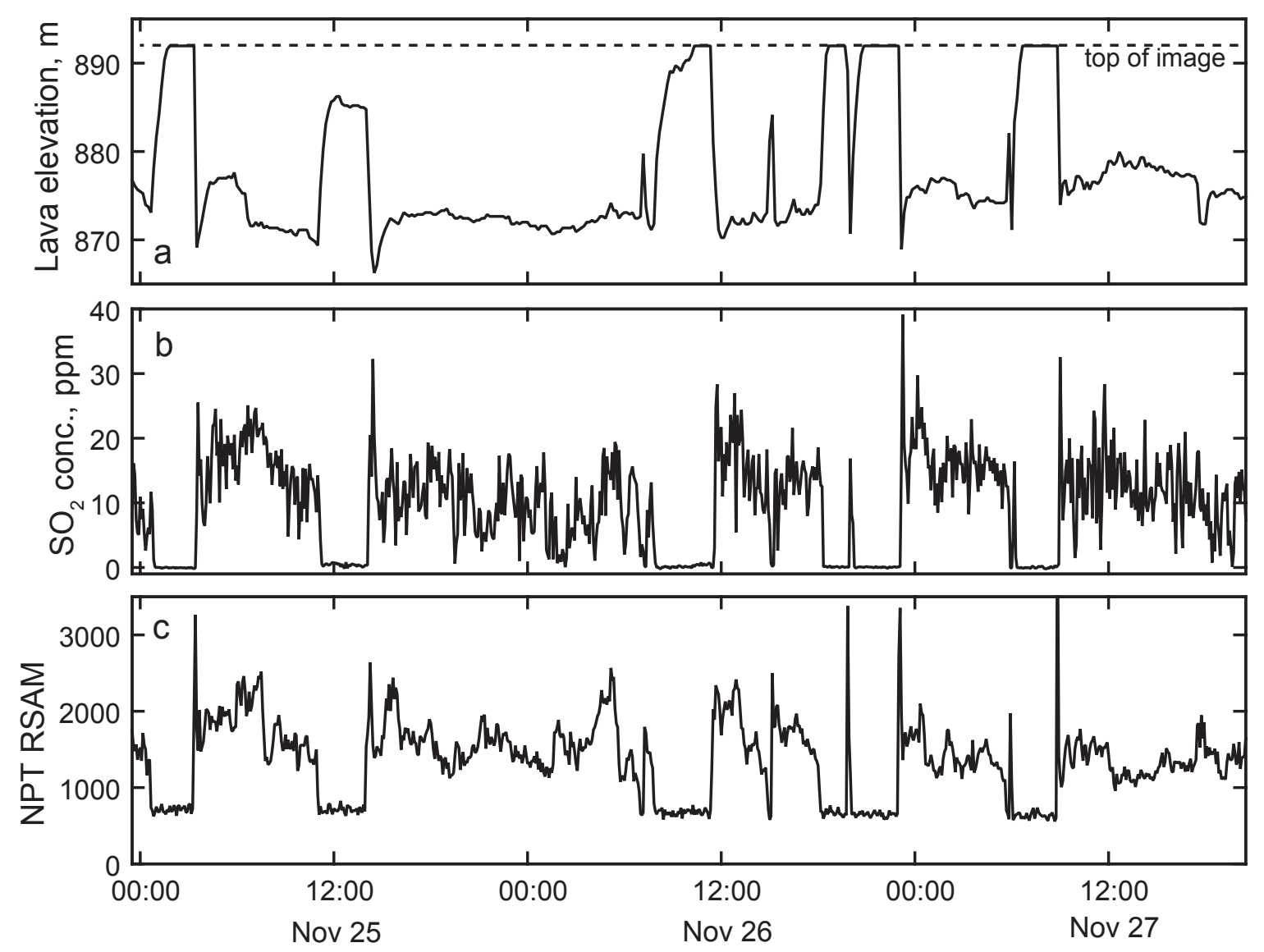

Figure 5 


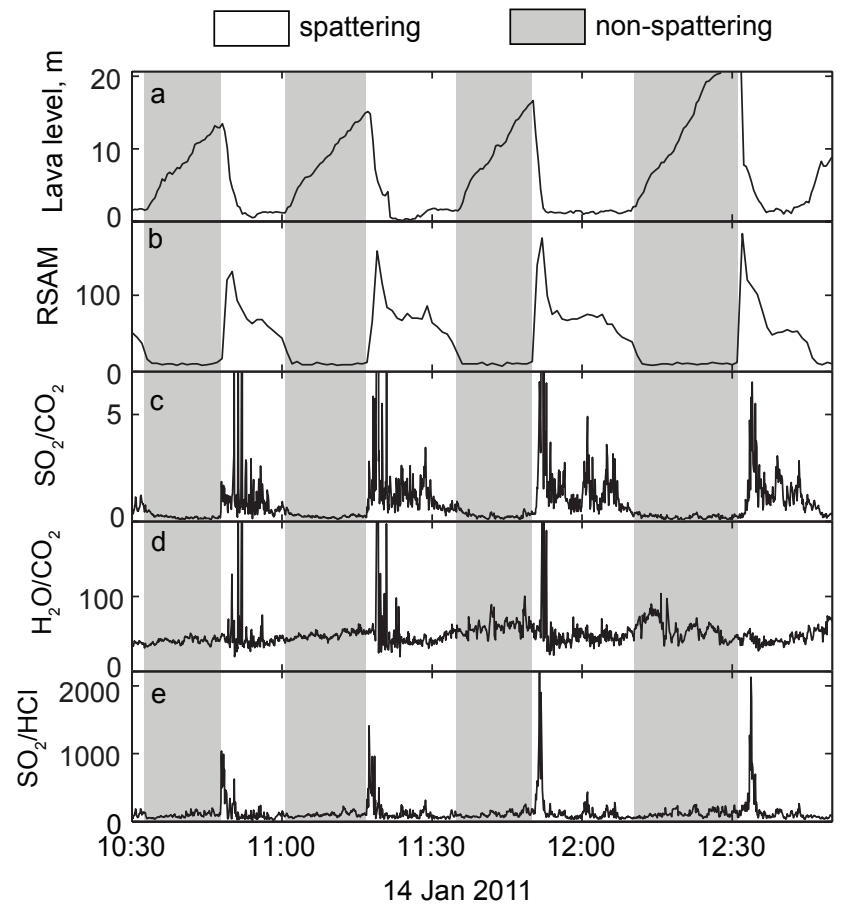

Figure 6 


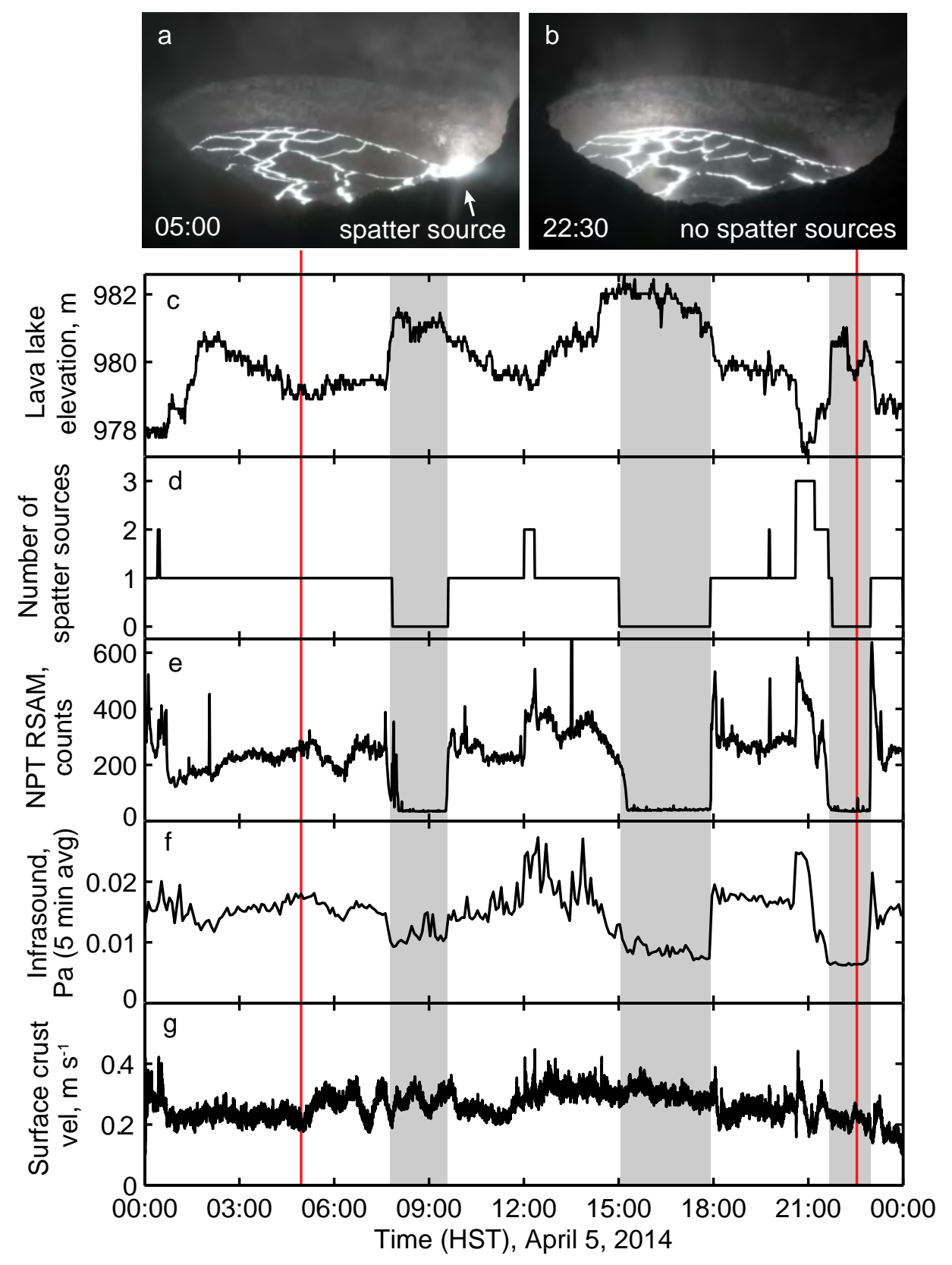

$\square$ Spattering phase $\square$ Non-spattering phase

Figure 7 

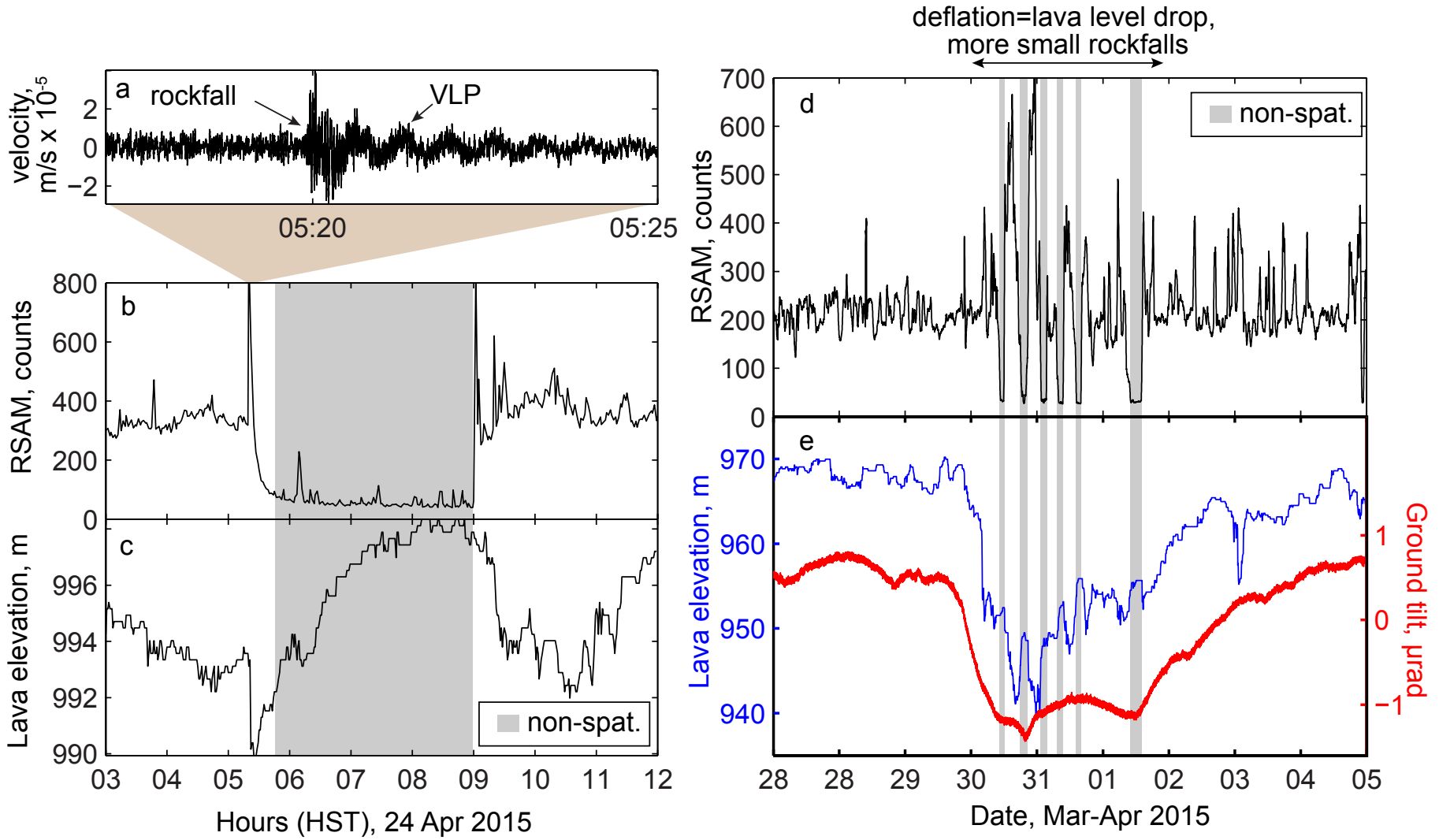

Figure 8 


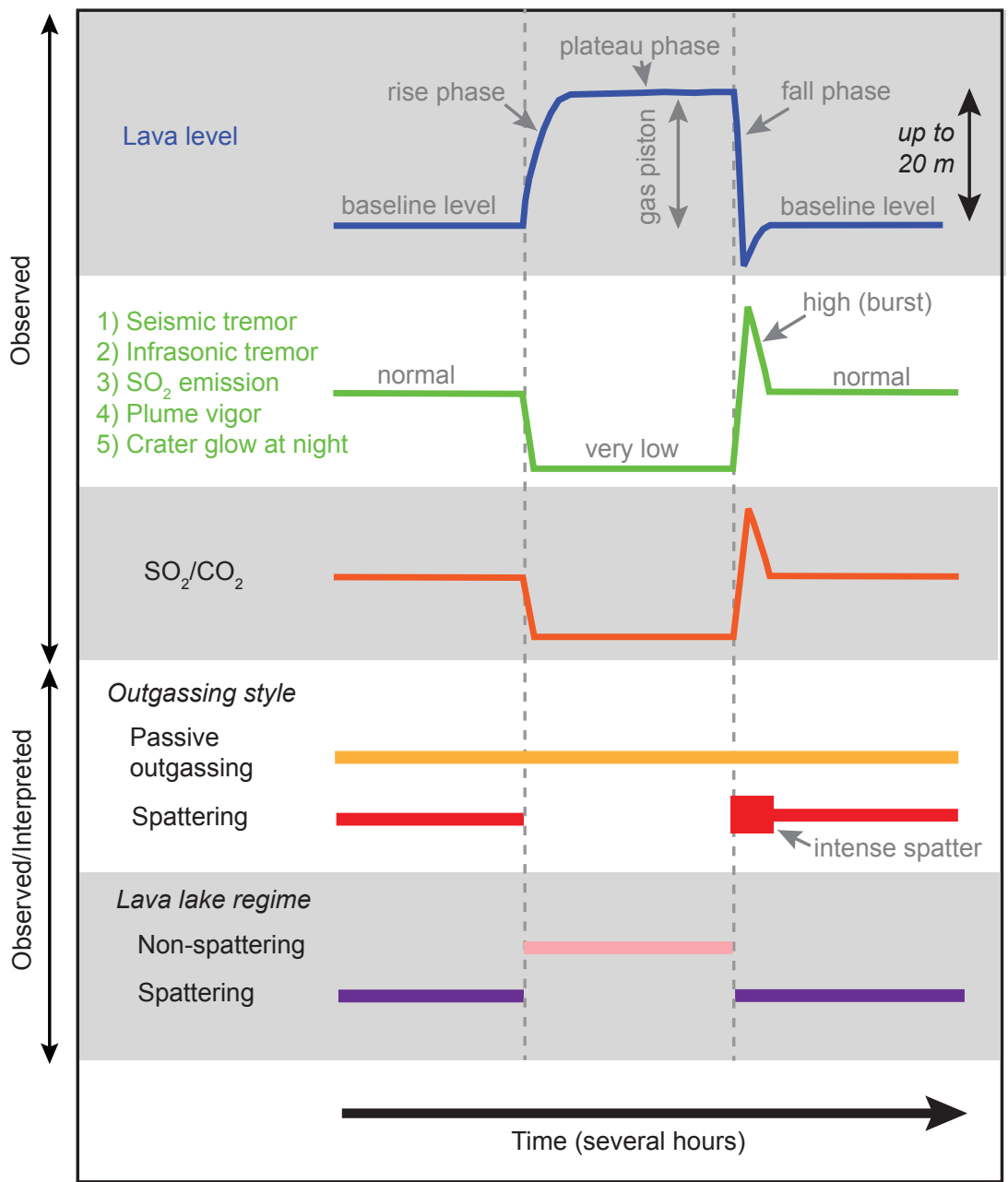

Figure 9 


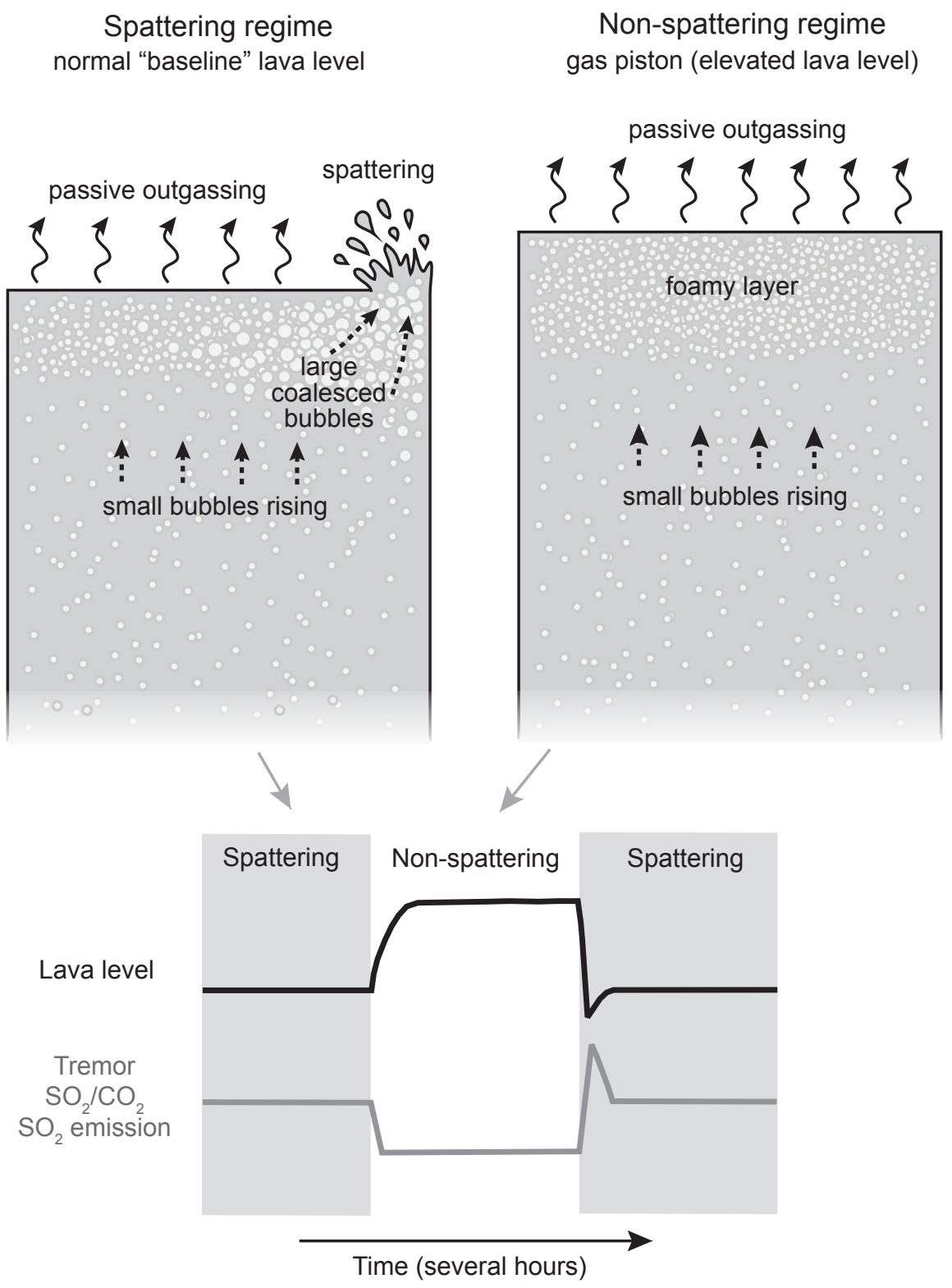

Figure 10 